\title{
Effect of Climacteric on Women Psychology and Behaviour
}

\author{
Supriya Roy and Pranati Srivastava* \\ Amity Institute of Pharmacy, Amity University Uttar Pradesh, India
}

Submission: October 16, 2017; Published: October 26, 2017

*Corresponding author: Pranati srivastava, Amity Institute of Pharmacy, Amity University Uttar Pradesh, India, Email: psrivastava6@lko.amity.edu

\section{Mini Review}

Climacteric commonly known as menopause is the time in a woman's life when there have been no menstrual periods for 12 consecutive months and no other biological or physiological cause can be identified. It is the end of fertility, hence also called the «change of life» that occurs eventually in all women with or without the presence of distressing symptoms. Natural menopause occurs due to decrease production of the sex hormones estrogen and progesterone, decreased ovarian function, depleted response of follicles within the ovaries to respond to follicle stimulating hormone (FSH). Induced menopause occurs if the ovaries are surgically removed or get damaged by radiation or drugs. Premature ovarian failure results due to various factors, including chromosomal abnormalities like turners syndrome, autoimmune disease like diabetes, thyroid disorders and viral infections. Menopause is associated with anatomical and physiological leading to various psychological changes that often influence normal behavior of the aging female. Some women may experience symptoms of menopause, while others experience few or multiple physical and psychological symptoms.

The various physical and emotional symptoms reported by women at the time of the menopause include weight gain, irregular and/or heavy periods, hot flushes, palpitations night sweats, headaches, insomnia, and mood swings. Hypothalamic response followed by declining ovarian estrogen production is responsible mechanism for hot flushes. The declining estrogen state induces hypophysiotropic neurons of the hypothalamus to release gonadotropin-releasing hormone which in turn stimulates release of luteinizing hormone (LH). The LH has vasodilatory effects, which leads to flushing. Urinary symptoms include thining and drying of urethral tissue leading to increased risk of urinary tract infections, urinary incontinence and frequent urination whereas vaginal symptoms include vaginal dryness, itching, irritation, decreased libido, vaginal infections.
Gastrointestinal symptoms include distress, indigestion, flatulence, gas pain, nausea [1].

Women frequently complain of waking up during their sleep and other psychological symptoms such as loss of confidence, forgetfulness, impaired concentration, confusion, anxiety, nervousness, depression, psychosexual dysfunction and relationship problems. Other symptoms include sudden bouts of bloat, tinnitus, hair loss or thinning, dizziness, increase in allergies, light-headedness, loss of balance, tingling in the extremities, changes in fingernails gum problems, increased bleeding, burning tongue, burning roof of mouth, bad taste in mouth, change in breath odor, changes in skin texture. Menopause is also associated with greater risk for cardiovascular disease, stress and osteoporosis and changes in physical and psychological health. A number of different treatments are used to alleviate menopausal symptoms, including lifestyle changes, medications such as hormonal preparations and complementary medicine. Hormone therapy and bioidentical hormone preparations containing hormones that have the same chemical formula as those made naturally in the body have been used to control the symptoms of menopause related to declining estrogen levels such as hot flashes and vaginal dryness Oral contraceptive pills to to treat irregular vaginal bleeding [2]. Antidepressant medications such as venlafaxine, fluoxetine, sertraline, citalopram and anti seizure drugs like gabapentin have shown to decrease the severity of hot flashes in some women. Medications like ibadronate, alendronate raloxifene increases bone strength. The risk of heart disease and osteoporosis can be minimized by taking a healthy diet low in saturated fat and salt and rich in calcium and vitamin $\mathrm{D}$

Home remedies include soy beans, chick peas, and lentils that contain is flavones, genistein and daidzein which are considered to be the most potent estrogens of the phytoestrogens $[3,4]$. Vitamin E provides relief from mild hot flashes. Other 
supplements include black cohosh, wild yam and licorice. Women experience the menopause in widely varying ways. Some women breeze through a problem-free menopause, but most experience some symptoms ranging from mild to severe. Whatever the symptoms, help is available in a range of ways [5].

\section{References}

1. Borud E, White A (2010) A review of acupuncture for menopausal symptoms. Mauritias 66:131-134

This work is licensed under Creative Commons Attribution 4.0 License

DOI: 10.19080/PBSIJ.2017.07.555709
2. Bosworth HB, Bastian LA, Rimer BK, Siegler IC (2003) Coping styles and personality Domains related to menopausal stress. 13(1): 32-38.

3. Norton S, Chilcot J (2014) Cognitive-behavior therapy for menopausal symptoms (hot flushes and night sweats): moderators and mediators of treatment effects. Menopause 21(6): 574-578.

4. Beral V, Bull D, Reeves G (2005) Endometrial cancer and hormone replacement therapy in the million women study. Lancet 365: 15431551.

5. https://www.womens-health-concern.org/help-and-advice/ factsheets/menopause/

\section{Your next submission with Juniper Publishers will reach you the below assets}

- Quality Editorial service

- Swift Peer Review

- Reprints availability

- E-prints Service

- Manuscript Podcast for convenient understanding

- Global attainment for your research

- Manuscript accessibility in different formats

( Pdf, E-pub, Full Text, Audio)

- Unceasing customer service

Track the below URL for one-step submission https://juniperpublishers.com/online-submission.php 